\title{
Detailed Kinetic Mechanism of CNG Combustion in an IC Engine
}

\author{
Muhammad Mansha ${ }^{1 *}$, Javed Syed Hassan ${ }^{1}$, Anwar Rashid Saleemi ${ }^{1}$, Badar M. Ghauri ${ }^{2}$ \\ ${ }^{1}$ Department of Chemical Engineering, University of Engineering and Technology, Lahore, Pakistan \\ ${ }^{2}$ Institute of Space Technology, Islamabad, Pakistan \\ E-mail: "muhammad_mansha@uet.edu.pk \\ Received March 25, 2011; revised April 29, 2011; accepted May 10, 2011
}

\begin{abstract}
In this study, the four kinetic reaction mechanisms were developed to simulate the formation of pollutant species in CNG fired IC engine. The reactions were generated using EXGAS and coupled with Leed's NOx reactions to develop four kinetic mechanisms. These reaction mechanisms described the combustion of natural gas at low (below $800 \mathrm{~K}$ ) to high (above $1000 \mathrm{~K}$ ) temperature in combustion chamber. The simulation studies predicted that the maximum cylinder pressure was achieved up to $18.0 \mathrm{~atm} \& 40.0 \mathrm{~atm}$ under fuel leaner conditions $(\varphi \approx 0.6)$ and fuel rich conditions $(\varphi=1.13$ to 1.3$)$ respectively. The simulation based data was compared with the experimental data (when engine was operated at $3000 \mathrm{rpm}, \varphi=1.0, P_{\text {inlet }}=0.67$ atm). For fuel rich conditions, high concentrations of $\mathrm{CO}$ were observed while $\mathrm{NO}_{\mathrm{x}}$ levels were lowered while the fuel leaner mixture produced the lower $\mathrm{CO}$ emissions and moderate levels of $\mathrm{NO}_{\mathrm{x}}$ emissions. The $\mathrm{NO}_{\mathrm{x}}$ and CO profiles depicted that Mechanism-I, Mechanism-II and Mechanism III seemed to be inappropriate for predicting the emissions in due to CNG combustion IC engine. The molded data for Mechanism-IV exhibited closer agreement with experimental measurements. The rate of production analysis identified the important reactions in each mechanism which were contributing in the formation of emission concentrations of pollutant species. Although each proposed mechanism illustrated some discrepancies among the profiles, Mechanism-IV (consisting of 208 reactions and 78 species) showed good agreement with experimental data for pressure, temperature and pollutant species profiles.
\end{abstract}

Keywords: Simulation, EXGAS, Mechanism, Oxidation, Species Profile

\section{Introduction}

Combustion is a key process of converting chemical energy to heat which is ultimately converted to mechanical energy to derive in IC engine. Due this combustion, pressure and temperature suddenly rise within the engine chamber which provides the driving force to push the piston back to produce the motion in the automobile [1]. Zheng et al. [2] discussed the application of Compressed Natural Gas (CNG) in light-duty engines. The authors concluded that the direct injection of CNG has shown better results in the thermal efficiencies comparable to those attained by high compression ratio. It was also concluded that the $\mathrm{CNG}$ fired engines produced lower $\mathrm{NO}_{\mathrm{x}}$ emissions while maintaining the smoke-free operation of Spark Ignition (SI) engines. To meet more stringent emission regulations, there are still many technical obstacles are required to be resolved in reducing the emissions both $\mathrm{NO}$ and $\mathrm{CO}$ simultaneously emitted from the internal combustion engine as discussed by Aslam et al. [3]. In the recent decade, $\mathrm{CNG}$ has been promoted as a promising clean fuel alternative to spark ignition engines because of its relatively high octane level. Lean burning of CNG in SI engines has the potential to improve thermal efficiency and reduce emissions compared with the burning of gasoline. Recently, an in-depth understanding of the physical and chemical processes is required to speed up the greener engine designs.

In literature, it is reported that many research groups recently have been working on natural gas-fuelled engines worldwide via experimental work or through simulation studies. For example; Shiga et al. [4] have investigated the characteristics of emissions from $\mathrm{CNG}$ direct injection combustion using experiment on a rapid com- 
pression-machine. In study cited at [5], Computational Fluid Dynamics (CFD) codes have been utilized to study the fuel combustion. Kusaka et al. [6] have investigated the dual fuel engine for both diesel and natural gas engine. Ando et al. [7] has carried out the computational analysis of combustion with self-ignited natural gas engine. Zheng et al. [2] have studied combustion process and fluid flow in a compression ignition natural gas engine with separated chamber using the CFD code. These CFD based studies required the reaction mechanisms to study the turbulence, flame development, flame propagation etc in combustion of various fuels using Fluent, ANSYS etc. In the literature, several detailed mechanisms [8-13] and reduced mechanisms [14-20] for methane $\left(\mathrm{CH}_{4}\right)$ combustion exist. The reported studies discussed the reaction mechanisms of single component hydrocarbon fuels such as methane, butane, octane, hydrogen etc. [21-26].

Mansha et al. has implemented the oxidation mechanisms of methane in IC engine and predicted the combustion temperature and pressure in the combustion chamber of the IC engine [27]. In this study, authors successfully predicted the emission profiles of $\mathrm{CO}$ using the GRI 3.0 mechanism and concluded that the kinetic mechanisms can be implemented in IC engine to simulation combustion process. In another study, the authors developed the kinetic mechanisms of CNG and simulation based investigation of $\mathrm{CNG}$ combustion was carried out [28].

CNG is multi-component (mixture of $\mathrm{CH}_{4}, \mathrm{C}_{2} \mathrm{H}_{6}, \mathrm{C}_{3} \mathrm{H}_{8}$, $\mathrm{C}_{4} \mathrm{H}_{10}, \mathrm{~N}_{2}, \mathrm{CO}_{2}$ ) fuel and the combustion mechanism of this mixture is needed to develop for the understanding the formation of various products gases especially pollutants (CO, NO. $\mathrm{NO}_{2}, \mathrm{NH}_{3}$ etc.).

In present study, reaction mechanisms (models) of CNG combustion in IC engine have been developed to predict the emission profiles of pollutants including Carbon monoxide (CO) and Oxides of Nitrogen (as NO and $\mathrm{NO}_{2}$ ). The model based results were validated through experimental measurements of the in-cylinder measurements of pressure, temperature and pollutant species on the dedicated experimental setup developed for this study.

\section{Experimental (Material and Methods)}

\subsection{Development of Kinetic Reaction Mechanisms of Natural Gas Combustion}

In this study, four kinetic reaction mechanisms were generated using EXGAS (an automatic mechanism generation tool). The EXGAS has three types of input (reactants, kinetic data and thermo-chemical data) to generate the reaction mechanisms of natural gas combustion. The reacting mixture species (as input to the EXGAS) have special one dimensional (1D) notation [29]. The software has built-in-notations for methane, ethane species as base species. These 1D notation were linked by the computer to an internal representation, which allows species reactants and products) to be stored in a unique format by using a canonicity algorithm. Further details of mechanism generation of EXGAS exist in User's Guide of the EXGAS [23]. The mechanisms generated were composed of a) $\mathrm{C}_{0}-\mathrm{C}_{1}-\mathrm{C}_{2}$ reaction base b) primary reaction mechanism in which the species in the initial gas mixture are taken as the reactants and c) secondary mechanism which contain reactions of inputs are the molecular products of the primary mechanism. The types of considered in each of each of the four kinetic reaction mechanisms are given in Table 1 . The types of primary molecules formed during the combustion of low hydrocarbons include Monohydroperoxides $(\mathrm{OOH})$, Dihydroperoxydes $(\mathrm{OOH})_{2}$, Allylic molecules YH, Ethers $(\mathrm{O}), \mathrm{Ke}$ tones $(\mathrm{CO})$, aldehydes $(\mathrm{CHO})$ etc are given in Table 2. Each of the four EXGAS generated reaction mechanisms were coupled with Leeds $\mathrm{NO}_{\mathrm{x}}$ Mechanism 2.0

(http://www.chem.leeds.ac.uk/Combustion/nox.htm).

Mechanism-I is a comprehensive reaction mechanism containing reactions feasible at range of temperature conditions (below $800 \mathrm{~K}$ and above $1000 \mathrm{~K}$ ). This mechanism is composed of 935 elementary reactions and 185 species. Mechanism-II is a high temperature (above $1000 \mathrm{~K}$ ) reaction mechanism and consists of 124 species and 792 elementary reactions. This mechanism composed of that type of reaction feasibly at high temperature during the combustion of natural gas. MechanismIII is a low tmperature (below $800 \mathrm{~K}$ ) reaction mechanism and consists of 152 species and 864 elementary reaction. Mechanism-IV is developed by the simplification of Mechanism-I by the chemical lumping technique. By this technique, the reaction steps with similar reactants and products have been eliminated. This reaction model is consisting of only 72 species and 208 elementary reactions. The proposed reaction mechanisms were used to simulate the combustion of natural gas under various temperature conditions and to predict the emissions.

\subsection{Simulation of Natural Gas (as CNG) Combustion Using Kinetic Reaction Mechanisms in IC Engine}

The combustion of CNG in IC engine was simulated using CHEMKIN 4.1.1 simulation package. It is a powerful set of software tools used to study reacting flows, such as those found in combustion, catalysis, chemical 
Table 1. Primary reactions in different reaction mechanisms (generated by EXGAS) for natural gas oxidation.

\begin{tabular}{clcccc}
\hline Sr. No & Types of Reactions & Mechanism-I & Mechanism-II & Mechanism-III & Mechanism-IV \\
\hline 1 & Unimolecular Initiations & $\sqrt{ }$ & $\sqrt{ }$ & $\sqrt{ }$ & $\sqrt{ }$ \\
2 & Bimolecular Initiations & $\sqrt{ }$ & $\sqrt{ }$ & $\sqrt{ }$ & $\mathrm{X}$ \\
3 & Additions & $\sqrt{ }$ & $\mathrm{X}$ & $\sqrt{ }$ & $\mathrm{X}$ \\
4 & Additions with Oxygen & $\sqrt{ }$ & $\mathrm{X}$ & $\sqrt{ }$ & $\mathrm{X}$ \\
5 & Isomerizations & $\sqrt{ }$ & $\sqrt{ }$ & $\sqrt{ }$ & $\mathrm{X}$ \\
6 & Decomposition of OOQOOH & $\sqrt{ }$ & $\mathrm{X}$ & $\sqrt{ }$ & $\mathrm{X}$ \\
7 & Beta-scissions & $\sqrt{ }$ & $\sqrt{ }$ & $\sqrt{ }$ \\
8 & Decompositions to O-rings & $\sqrt{ }$ & $\mathrm{X}$ & $\sqrt{ }$ & $\sqrt{ }$ \\
9 & Oxidations & $\sqrt{ }$ & $\sqrt{ }$ & $\sqrt{ }$ \\
10 & Branching & $\sqrt{ }$ & $\sqrt{ }$ & $\sqrt{ }$ \\
11 & Metatheses & Combinations & $\sqrt{ }$ & $\sqrt{ }$ & $\sqrt{ }$ \\
\hline
\end{tabular}

Table 2. Different primary molecules classes in four reaction mechanisms (generated by EXGAS) of natural gas oxidation.

\begin{tabular}{|c|c|c|c|c|c|}
\hline Sr.No & PRIMARY MOLECULES CLASSES & Mechanism-I & Mechanism-II & Mechanism-III & Mechanism-IV \\
\hline 1 & Monohydroperoxides (ooh) & 26 & 4 & 6 & 4 \\
\hline 2 & Dihydroperoxydes (ooh)2 & $\mathrm{X}$ & $\mathrm{X}$ & $\mathrm{X}$ & $\mathrm{X}$ \\
\hline 3 & O-rings & $\mathrm{X}$ & $\mathrm{X}$ & $\mathrm{X}$ & $\mathrm{X}$ \\
\hline 4 & Allylic molecules YH & 6 & 3 & 2 & 2 \\
\hline 5 & Alkohols (oh) & 5 & 5 & 5 & 5 \\
\hline 6 & Ethers (o) & 1 & 1 & 1 & 1 \\
\hline 7 & Ketones (co) & 10 & 5 & 5 & 5 \\
\hline 8 & Aldehydes (cho) & 11 & 5 & 5 & 5 \\
\hline
\end{tabular}

vapour deposition, and plasma etching. It consists of rigorous gas-phase and gas-surface chemical kinetics in a variety of reactor models that can be used to represent the specific set of systems of interest [30].

The IC engine module (of CHEMKIN 4.1.1) is a model developed by supposing that the combustion chamber is a 0-D closed system which assumes the complete homogenous gas mixture as working fluid. The simulation is only valid within the time period when both intake and exhaust valves are closed. Conventionally, the engine cylinder events are expressed in crank rotation angle relative to the top dead center (TDC). The intake valve close (IVC) time of our test engine is -142 degrees (crank angle) before TDC (BTDC). The general inputs of the simulation (Table 3 ) are:

- Chemical reaction mechanisms with Arrhenius Coefficients,

- Thermodynamic data,

- Molar fractions of reactive species (Natural Gas: $\mathrm{CH}_{4}$, $\mathrm{C}_{2} \mathrm{H}_{6}, \mathrm{C}_{3} \mathrm{H}_{8}$, and air $-\mathrm{O}_{2}, \mathrm{~N}_{2}$ ) for various equivalence ratios and

Geometrical parameters of the IC Engine (cylinder displaced volume, clearance volume, crank to connecting rod ratio etc.).

The outputs extracted from the simulation studies were:

- Temperatures profiles,

- pressures profiles,

- Main species profiles

\subsection{Experimental Setup}

An experimental set up was designed and developed to measure the engine in-cylinder pressure, temperature and concentration of carbon monoxide (CO) and oxides of nitrogen (as $\mathrm{NO}$ and $\mathrm{NO}_{2}$ ) when the engine is fully operated on $\mathrm{CNG}$. The experimental results were compared with those obtained by the simulation studies using the proposed kinetic reaction mechanisms.

The engine used in the present study is a spark ignition IC engine that is widely used in three-wheeled automobile rickshaw in Pakistan (called a $\mathrm{CNG}$ rickshaw). The engine is having bi-fuel system operating on both petrol and CNG. The schematic diagram of this bi-fuel system 
Table 3. Typical engine geometrical input parameters and initial gas (feed) mixture composition.

\begin{tabular}{|c|c|c|c|c|}
\hline \multirow[t]{2}{*}{ Sr. No } & \multicolumn{2}{|c|}{ Engine Geometrical Input Parameters } & \multicolumn{2}{|c|}{ Initial Gas Mixture (CNG Composition), Mole Fraction } \\
\hline & Parameter (unit) & Value & Component & Mole Fraction \\
\hline 1 & Cylinder Volume $\left(\mathrm{cm}^{3}\right)$ & 63 & Methane $\left(\mathrm{CH}_{4}\right)$ & 0.8903 \\
\hline 2 & Displaced Volume $\left(\mathrm{cm}^{3}\right)$ & 56.52 & Ethane $\left(\mathrm{C}_{2} \mathrm{H}_{6}\right)$ & 0.0105 \\
\hline 3 & Clearance Volume $\left(\mathrm{cm}^{3}\right)$ & 6.48 & Propane $\left(\mathrm{C}_{3} \mathrm{H}_{8}\right)$ & 0.027 \\
\hline 4 & Cylinder Diameters $(\mathrm{cm})$ & 14.67 & Butane $\left(\mathrm{C}_{4} \mathrm{H}_{10}\right)$ & 0.0017 \\
\hline \multirow{2}{*}{5} & \multirow{2}{*}{ Crank to Connecting Rod Ratio } & \multirow{2}{*}{1.632} & Nitrogen $\left(\mathrm{N}_{2}\right)$ & 0.072 \\
\hline & & & Carbon Dioxide $\left(\mathrm{CO}_{2}\right)$ & 0.026 \\
\hline
\end{tabular}

is shown in Figure $\mathbf{1}$ and lab view is shown in Figure 2.

The other details of this experimental setup and specifications of engine are given in Tables 4 and 5.

The in-cylinder pressure and temperature were measured using a special spark plug with a built-in pressure sensor and thermocouple. The spark plug used in this study is a diode laser based electric spark plug and has a fast transient pressure transducer (Kistler, Model 603B1). This sensor was combined with a charge amplifier (Kistler, Model 5010. A high precision angle displacement sensor with a one degree resolution was added to the crankshaft. The data acquisition for the pressure sensor was triggered by the crank angle sensor such that a pressure measurement was taken every crank angle degree. During the pressure measurements, substantial variation was observed in consecutive operating cycles (One engine cycle consist of 4-strokes and completed in 0.0077 sec and swap $720^{\circ}$ crank rotation angle). The in-cylinder $\mathrm{CO}$ and $\mathrm{NOx}$ (as $\mathrm{NO}$ plus $\mathrm{NO}_{2}$ ) were determined through fast sampling valve. On the exhaust side, an emission analyzer (Test $350 \mathrm{XL}$ ) was used to determine the composition of the gases. The data was acquired at $100 \mathrm{~Hz}$ through a 12 bit data acquisition system. Eight channels of data collected are the time histories of the trigger signal (used as time reference) and cylinder pressure. Data for all individual tests are normalized based on the initial time reference signal. The data collection is performed with a personal computer equipped with an AJD board (Data Translation, Model DT2837).

\section{Results and Discussion}

An IC engine performance was characterized by measuring the profiles of in-cylinder pressure and temperature variations during engine cycle. The formation of carbon monoxide $(\mathrm{CO})$ and oxides of nitrogen (as $\mathrm{NO}, \mathrm{NO}_{2}$ ) was studied.

The measured data of cylinder temperature, pressure and pollutants emission profiles (for $\mathrm{CO}, \mathrm{NO}, \mathrm{NO}_{2}$ ) were compared with the simulation (modeled) outcomes. During the measurements, significant variations in the selected parameters were observed within the combustion chamber. This comparison provided the baseline information for the selection of an appropriate kinetic model (mechanism) of oxidation of natural gas (as $\mathrm{CNG}$ ) in IC engine.

\subsection{The In-Cylinder Pressure and Temperature}

The recorded pressure data was plotted versus crank angle (the time of complete cycle duration which fourstroke was converted to crank angle position with simulation model (Chemkin 4.1.1). This variation in measurements is plotted for the results obtained when engine operating conditions were under stoichiometric $(\varphi=1.0)$ conditions and at $3000 \mathrm{rpm}$. In Figure 3, each plot showed the similar pattern of variations of chamber pressure for each cycle while the major variations were observed for peak pressures during the combustion process occurring from $-20^{\circ}$ to $0^{\circ}$ crank angle. The plot has not smooth variation in the each profile (both model based and experimental based data) which indicate the occurrence of unpredicted reactions and sudden release of energy as discussed in reference cited at [1]. The average measured cylinder pressure varied from $0.61 \mathrm{~atm}$ to $32.62 \mathrm{~atm}$ for six (06) consecutive engine cycles. Under fuel-lean conditions $(\varphi \approx 0.6)$, the maximum cylinder pressure was reached up to $18.0 \mathrm{~atm}$. Similarly, for fuel-rich conditions, a maximum pressure of about 40.0 atm was achieved for equivalence ratio of $\varphi=1.13$ and 1.3. Unexpectedly, there was lower maximum cylinder pressure $(\approx 38 \mathrm{~atm})$ was observed at $\varphi \approx 1.4$.

This high cylinder pressure indicates the degree of completion of the combustion which depicts the maximum release of the energy from the fuel contents during combustion. Similarly, the low pressure indicates the in-complete combustion which means that net heat of reaction released is low [1]. The cylinder pressure is studied by a number of researchers [31-35] and obtained the pressure profiles as shown in Figure 3. For example, Ridha et al. [31] in the study of three chemical kinetic mechanisms of methane combustion obtained the similar pressure profiles under stoichiometric conditions. Li Cao et al. [30] simulated the engine flow using the turbulence model 


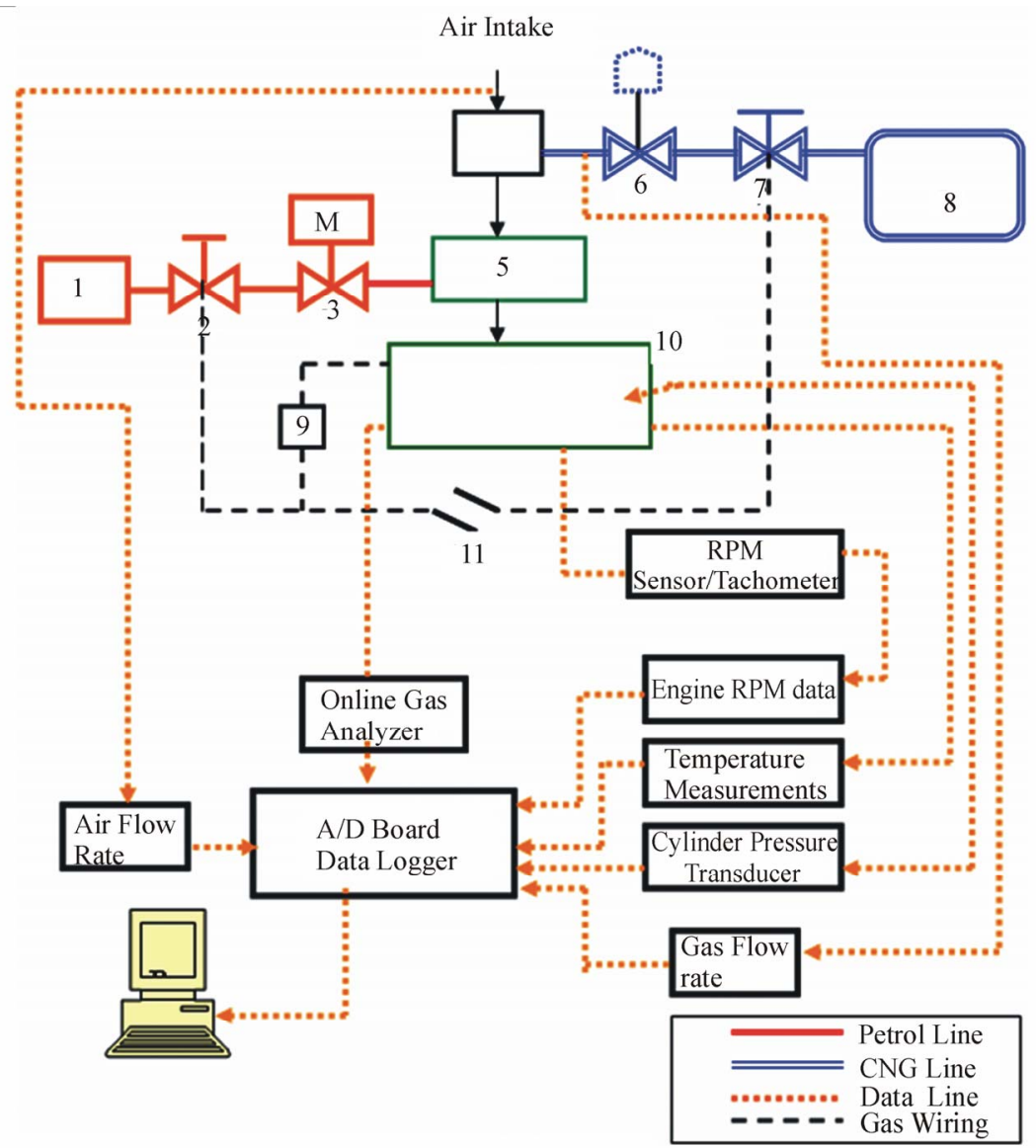

Figure 1. Schematic diagram of experimental setup.

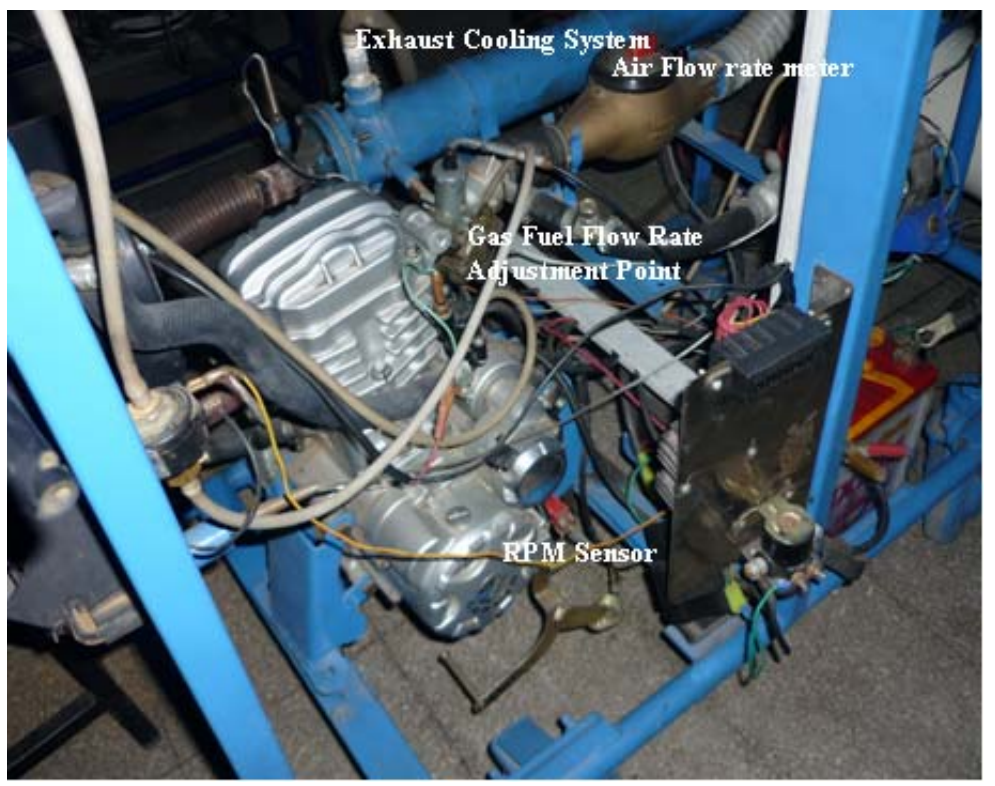

Figure 2. Lab view of experimental setup.

and correlated the engine pressure variation with the heat released during the engine cycle. Ibrahim et al. [33] in- vestigated the cylinder pressure for various engine speeds and obtained the pressure profiles experimentally for 
Table 4. Experimental setup components.

\begin{tabular}{clcl}
\hline No & Component & No & Component \\
\hline 1 & Petrol Tank & 7 & CNG Solenoid Valve \\
2 & Petrol Solenoid & 8 & GAS (CNG, Methane, Fuel B) Storage Tank \\
3 & Petrol Flow Meter & 9 & Spark Timing Advancer \\
4 & CNG Mixer & 10 & Spark Plug \\
5 & Carburetor & 11 & Fuel Selector switch \\
6 & CNG Pressure Regulator & & \\
\hline
\end{tabular}

Table 5. Specification tested engine used in 4-stoke automobile rickshaws.

\begin{tabular}{lc}
\hline Parameter & Typical Value \\
\hline Engine Capacity & $200 \mathrm{CC}$ \\
Compression Ratio & 10.51 \\
Bore, mm & 33.5 \\
Stroke, mm & 35.5 \\
Cylinder Volume $\left(\mathrm{cm}^{3}\right)$ & 63 \\
Displaced Volume $\left(\mathrm{cm}^{3}\right)$ & 56.52 \\
Clearance Volume $\left(\mathrm{cm}^{3}\right)$ & 6.48 \\
Cylinder Diameters $\left(\mathrm{cm}^{3}\right)$ & 14.67 \\
Crank to Connecting rod ratio & 1.632 \\
Carburetor & 2-barreldown-draft \\
& \\
Regulator & Specification of CNG carburetion system \\
Mixer & LANDI RENZO TN1-B-SIC \\
Spark advancer & Remote extractor \\
& STAP 51 \\
\hline
\end{tabular}
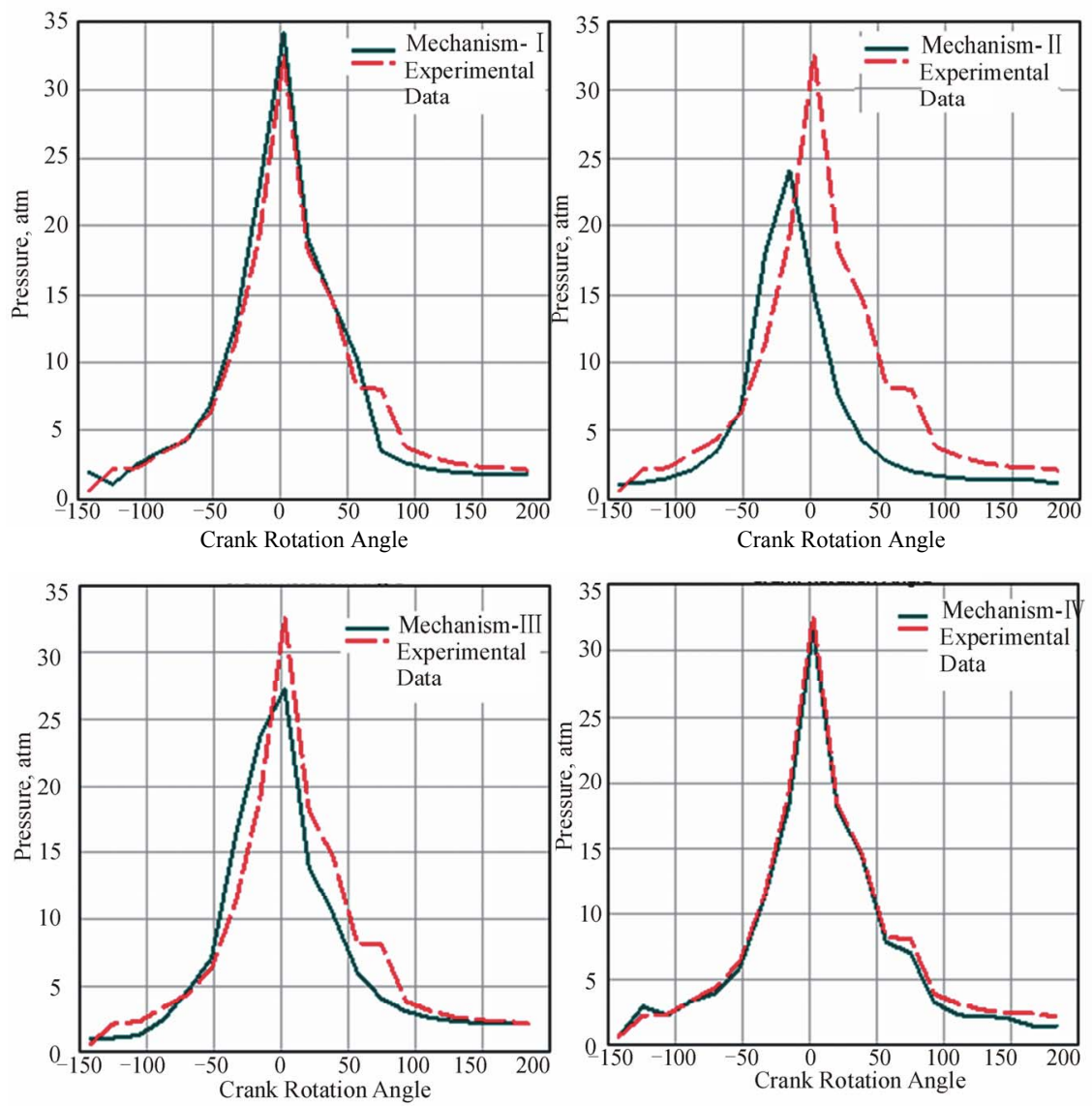

Figure 3. Pressure profiles for four proposed kinetic models (simulation with IC modules of Chemkin 4.1.1 and experimental cylinder pressure data. 
CNG fuel in IC engine.

It clear from Figure 3 that the curves for proposed kinetic Mechanism-I and Mechanism-IV shows similar behavior throughout the cycle but the profile of Mechanism-IV are much closer agreement with the experimental data plot. Although, the both the experimental and simulation profiles for Mechanism-IV do not follow the normal trend but the Mechanism-IV predicted the closer trend with the experimental trend. On the basis of pressure profiles (both simulation data and experimental data) for Mechanism-IV, it can be conclude that Mechanism-IV is an appropriate mechanism of CNG combustion in IC engine as shown experimental setup (Figure 1).

Figure 4 shows the variation of average cylinder temperature measured for six successive engine cycles (each cycle consists of 4-strokes). Mechanism-I over predict the chamber temperature (up to about $5000 \mathrm{~K}$ ) during the combustion of reacting mixture (CNG-Air) while Mechanism-II and Mechanism-III indicate the early start of the combustion which do not coincide with the experimental data.

According to Figure 4, the experimental data showed the good agreement with simulation results were obtained using Mechanism-IV. The average peaks cylinder temperature reached up to $4000 \mathrm{~K}$ while the engine was operating at $3000 \mathrm{rpm}, \varphi=1.0, P_{\text {inilet }}=0.67 \mathrm{~atm}$ for Mecha-
nism-IV. The initial temperature rises (up to $1600 \mathrm{~K}$ ) due to the compression stroke from $-100^{\circ}$ to $-20^{\circ}$ of crank angle position and after this there is substantial increase in the temperature which is due to start of combustion process (occurring between $-20^{\circ}$ and $2^{\circ}$ ). When expansion stroke starts, then fall of temperature was observed and it continued with higher gradient for exhaust stroke.

The effect of fuel/air equivalence ratio on the cylinder temperature has been investigated in the engine operating at $3000 \mathrm{rpm}, P_{\text {inilet }}=0.67 \mathrm{~atm}$. The plots in Figure 5 shows that a smooth trend of variation in cylinder temperature was observed for fuel rich conditions for equivalence ratios of $\varphi=1.1,1.3$ and 1.4.

The maximum peak temperature (about $4100 \mathrm{~K}$ ) was observed when the engine was achieved equivalence ratio of 1.3. The peak temperatures and pressure observed in the combustion cylinder are given in Table 6 along with mean values and St. Dev. in the data for various equivalence ratios.

\subsection{Investigation of Formation of Pollutant Species}

The formation of two criteria gaseous pollutants ( $\mathrm{CO}$ and $\mathrm{NO}_{\mathrm{x}}$ ) were studied in present research work. A fast response NO detector, based on the chemiluminescence

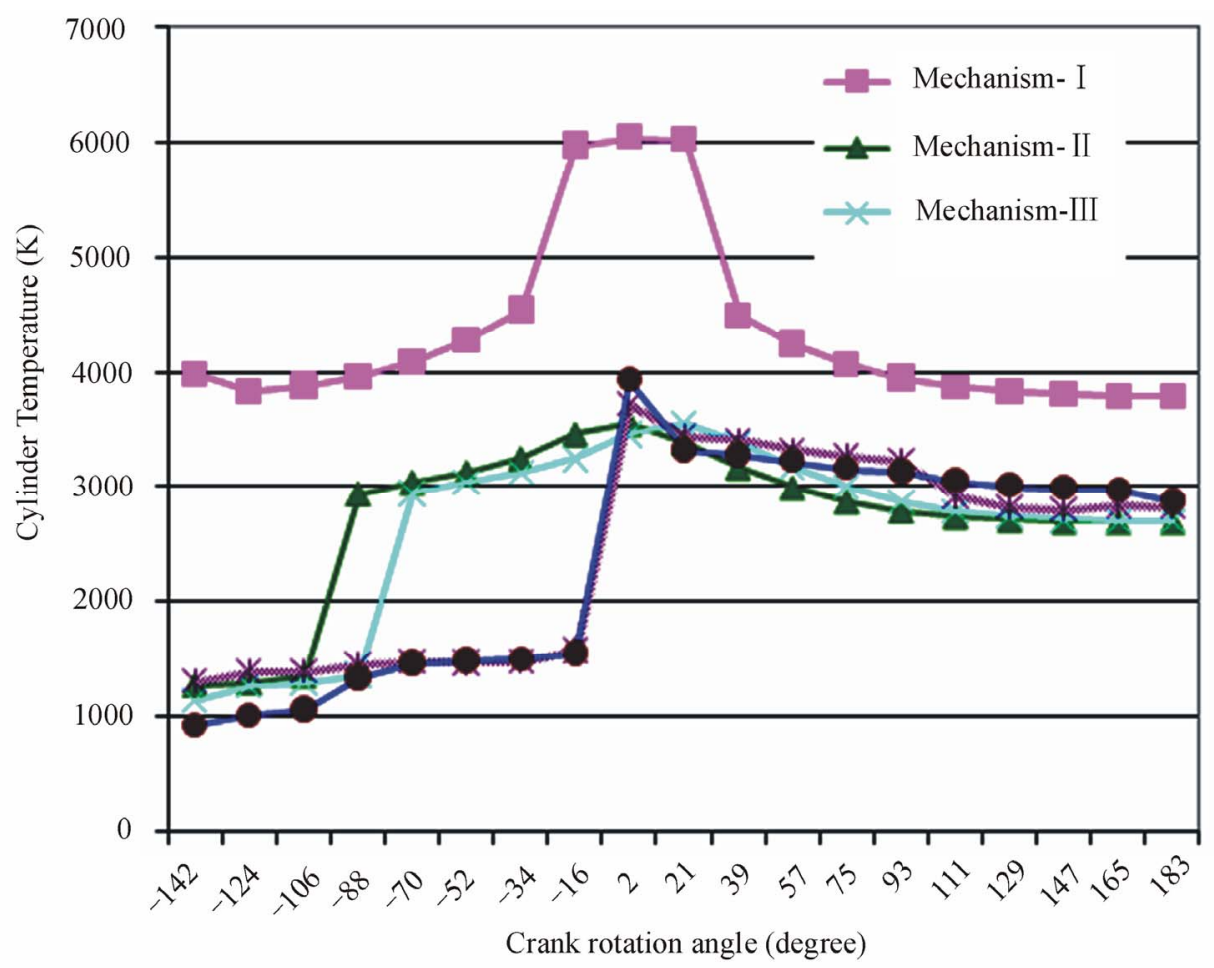

Figure 4. Cylinder temperature of predicted for four mechanisms and average of six (06) consecutive operating cycles of engine operating at $300 \mathrm{rpm}, \varphi=1.0, P_{\text {inilet }}=0.67 \mathrm{~atm}$. 

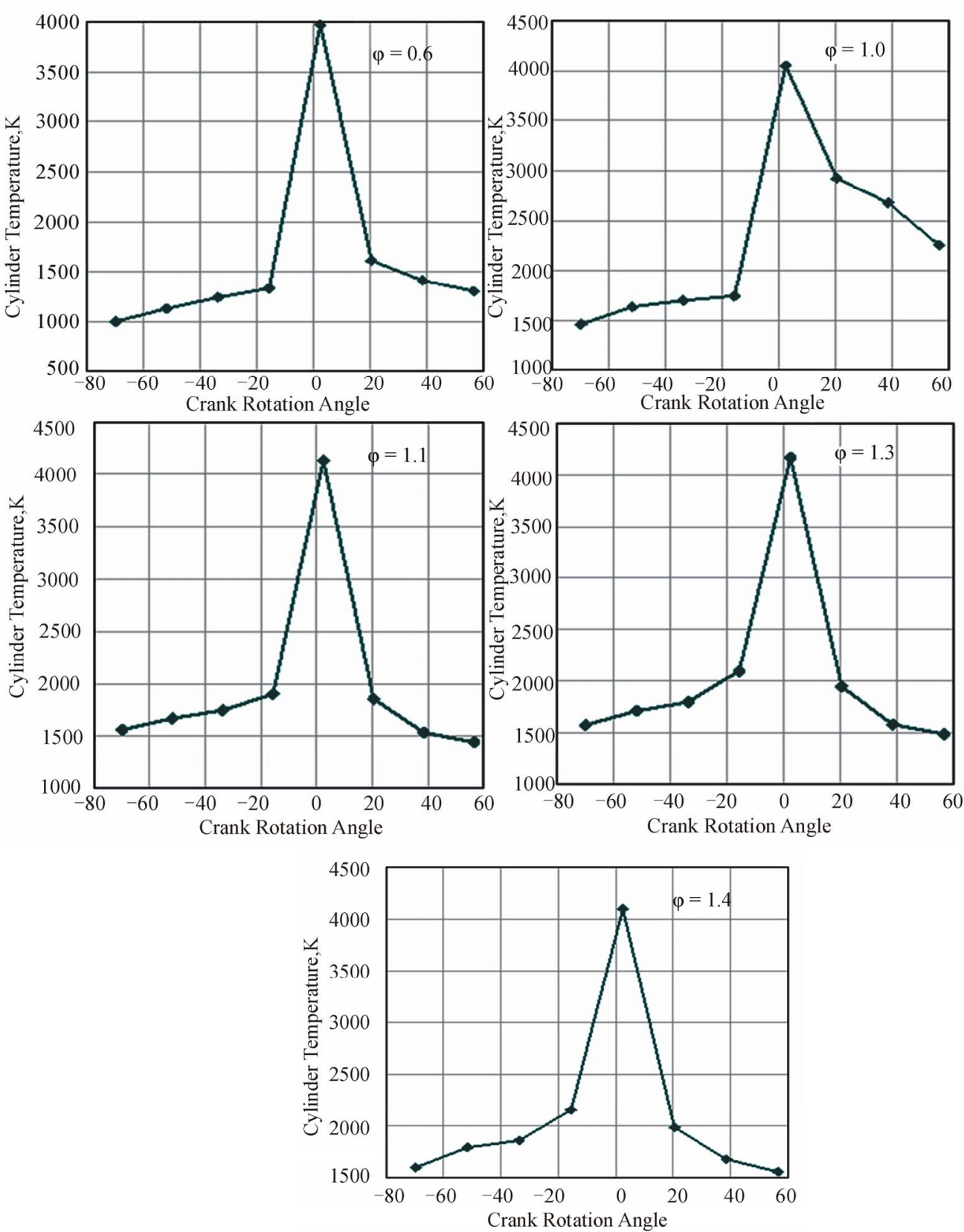

Figure 5. Measured cylinder temperatures at various equivalence ratios of CNG fired IC Engine operating at 3000 rpm, $P_{\text {inilet }}$ $=0.67$ atm.

Table 6. Peak cylinder temperature and pressure at various equivalence ratios.

\begin{tabular}{ccccccc}
\hline Equivalence Ratio $(\varphi)$ & \multicolumn{3}{c}{ Temperature, (K) } & \multicolumn{3}{c}{ Pressure, (atm) } \\
\cline { 2 - 7 } & Peak & Mean & St. Dev & Peak & Mean & St. Dev \\
\hline 0.6 & 3976.07 & 3587.14 & 676.14 & 31.06 & 8.27 & 8.75 \\
1.0 & 3994.09 & 3613.25 & 597.88 & 28.37 & 7.55 & 7.97 \\
1.13 & 4053.30 & 3753.77 & 656.50 & 30.30 & 8.06 & 8.52 \\
1.3 & 4102.4 & 3808.46 & 686.05 & 33.76 & 8.45 & 8.94 \\
1.4 & 4100.56 & 3783.11 & 711.84 & 32.87 & 8.68 & 9.27 \\
\hline
\end{tabular}


(CLD) method has been used to measure continuous, real-time levels of $\mathrm{NO}$ in the cylinder. The $\mathrm{NO}_{\mathrm{x}}$ concentrations data (as calculated as mole fraction of sum of $\mathrm{NO}$ and $\mathrm{NO}_{2}$ data) is plotted versus crank angle position as shown in Figure 6. The data was collected when engine was operated at $3000 \mathrm{rpm}$ under stoichiometric conditions (when $\varphi=1.0$ ).

The fluctuations in the $\mathrm{NO}_{\mathrm{x}}$ levels in the combustion chamber were observed after combustion process during expansion and exhaust phases. The $\mathrm{NO}_{\mathrm{x}}$ profile showed that maximum $\mathrm{NO}_{\mathrm{x}}$ concentrations were produced when engine was fired by the $\mathrm{CNG}$. The increase or decrease of the concentrations of $\mathrm{NO}_{\mathrm{x}}$ after combustion indicates occurring of the reactions during the expansion of the burned gas mixture but reactions consuming $\mathrm{NO}_{\mathrm{x}}$ molecules are seems to dominant the producer reactions. During the exhaust phase, the constant levels indicate the freezing of the $\mathrm{NO}_{\mathrm{x}}$ chemistry at the low temperature [1]. It can be concluded that higher $\mathrm{NO}_{\mathrm{x}}$ levels were observed at higher temperatures in the combustion chamber. The curves of Figures 6 and 7 illustrated that lower emissions were observed under lean mixture conditions $(\varphi<$ 1.0). The shapes of these curves showed the complexities emission controls. When engine operation becomes stable (usually when fuel flow increased and combustible mixture become fuel-rich), high concentrations of $\mathrm{CO}$ were observed while $\mathrm{NO}_{\mathrm{x}}$ levels were lowered. During the measurements, it was also observed that when engine was operated under load condition, leaner mixture produced lower $\mathrm{CO}$ emissions and moderate levels of $\mathrm{NO}_{\mathrm{x}}$ emissions.

Figures 7 and 8 also indicate that highest concentration of $\mathrm{NO}_{\mathrm{x}}$ were near the stoichiometric conditions and then become lower while $\mathrm{CO}$ level shows increasing trend. Maximum variation in the concentrations of these pollutants $\left(\mathrm{NO}\right.$ and $\mathrm{NO}_{2}$ ) is clearly shown in Figures 7 and 8.

There are two major sources of nitrogen to in fuel

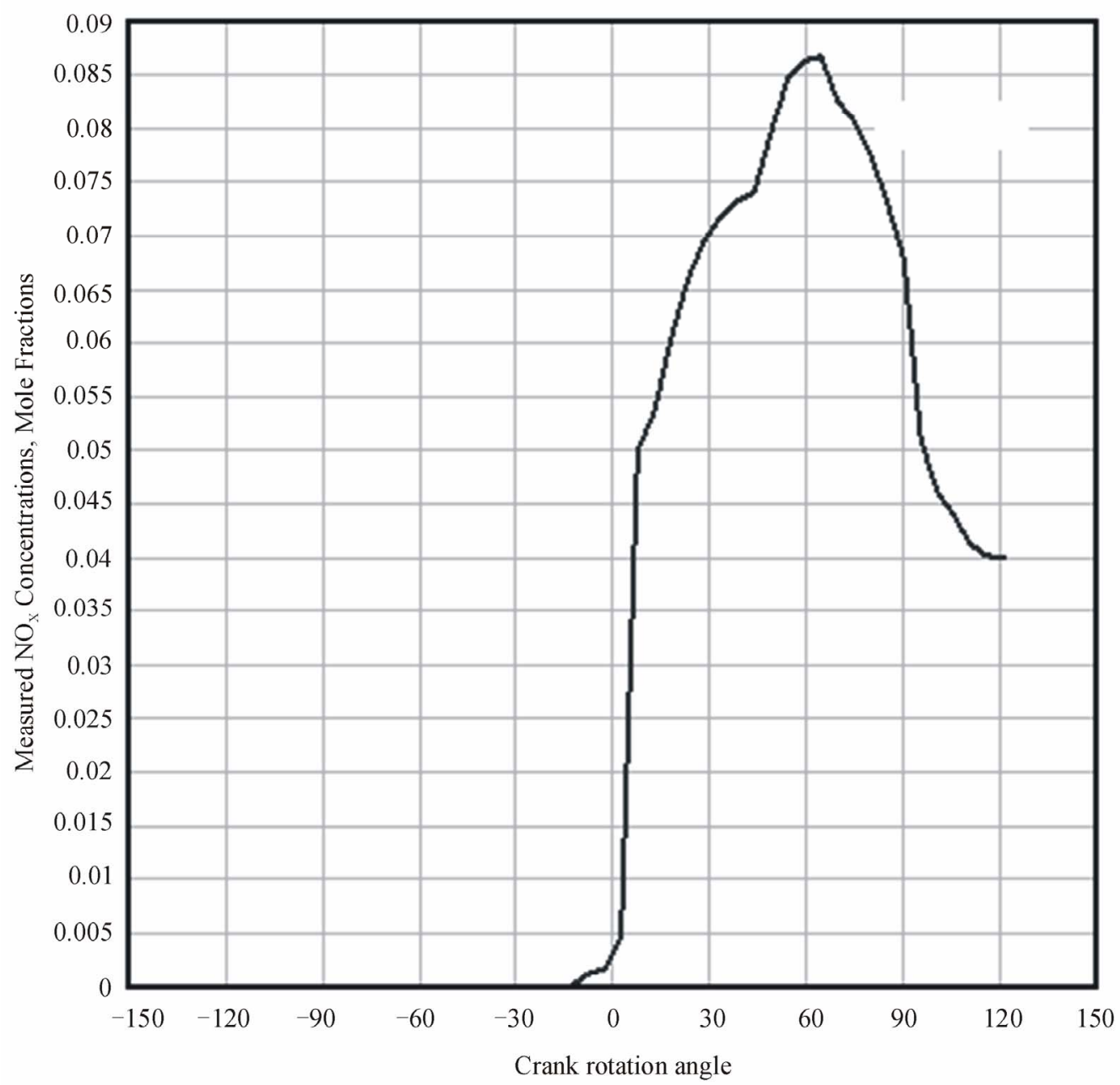

Figure 6. Measured $\mathrm{NO}_{\mathrm{x}}$ concentrations (in-cylinder) for three fuel (3000 rev/min, $\varphi=1.0$ and $\left.\boldsymbol{P}_{\text {inlet }}=\mathbf{0 . 6 7} \mathrm{atm}\right)$. 


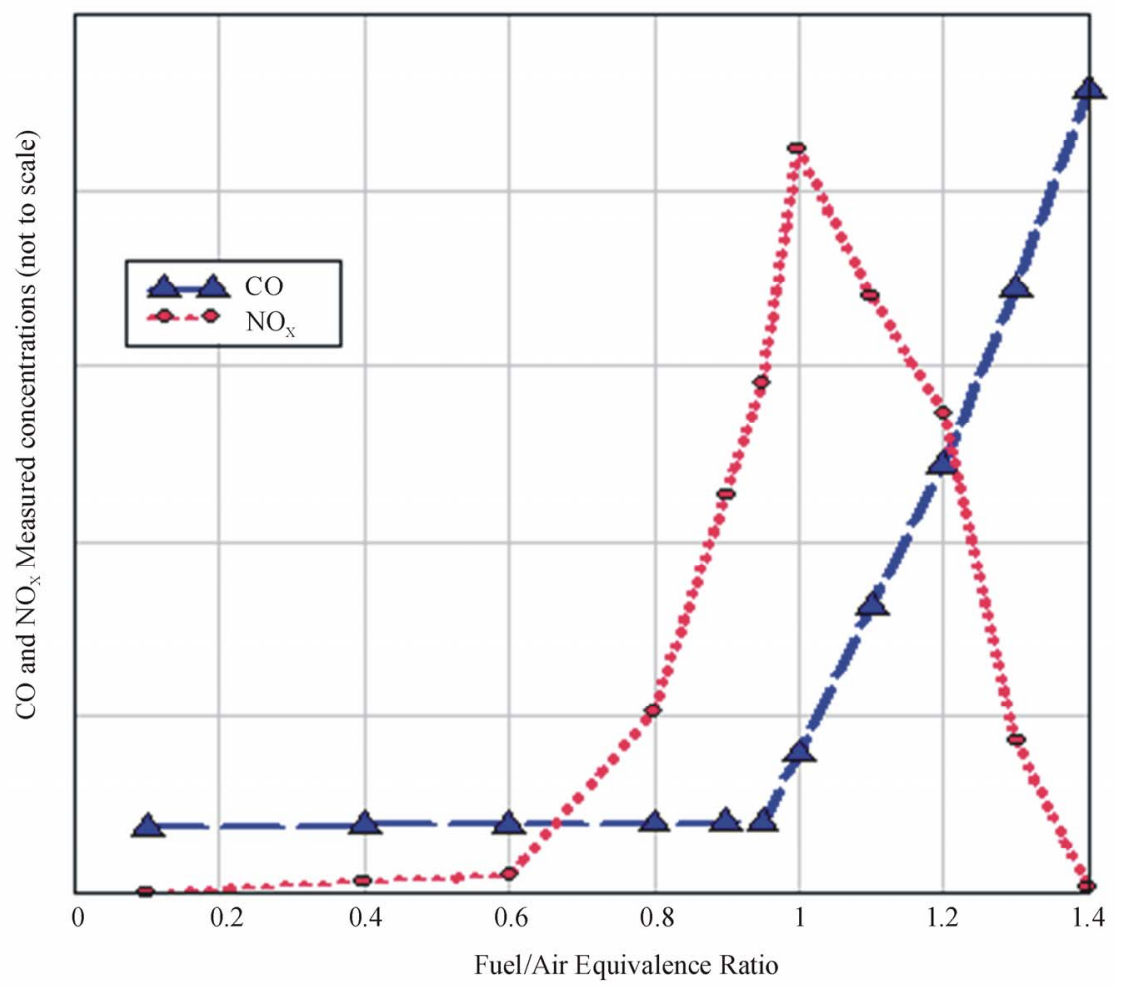

Figure 7. Variation of CO and NOx concentration in exhaust of CNG fired IC engine (200 CC) at various equivalence ratio (fuel/ratio).

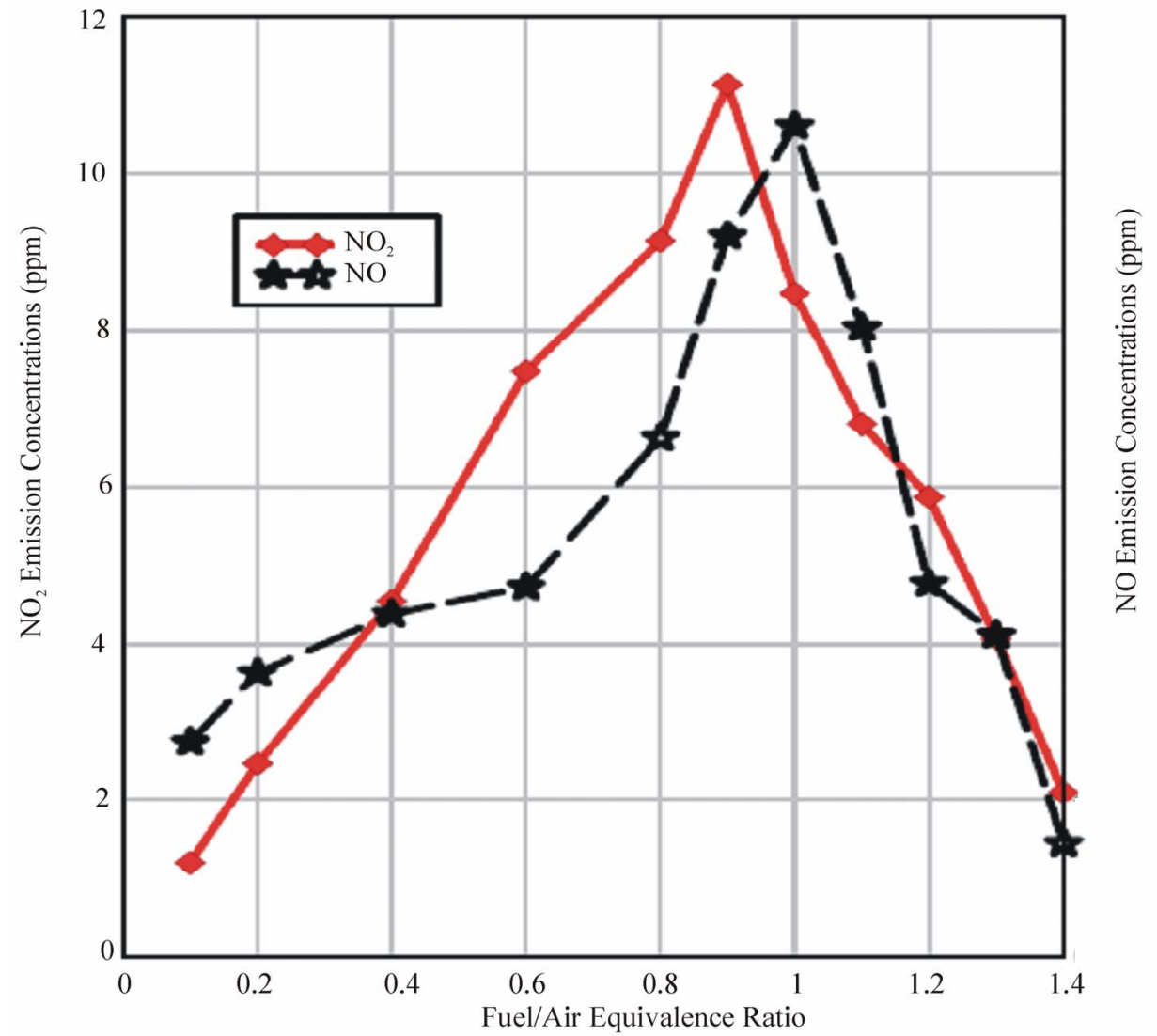

Figure 8. Variation in concentrations of $\mathrm{NO}$ and $\mathrm{NO}_{2}$ in engine exhaust as function of equivalence ratio. 
mixture (fuel nitrogen and air nitrogen) in pre-mixed combustion of $\mathrm{CNG}$ in IC engine. Studies [1] revealed that the fuel nitrogen is source of NO via different mechanisms.

Figure 9 shows the comparison of results of experimental data of in-cylinder NOx data of IC engine fired with $\mathrm{CNG}$ operating at $3000 \mathrm{rpm}$ and equivalence ratio of $\approx 1.0$ and simulation data of $\mathrm{NO}_{\mathrm{x}}$ (as mole fraction) obtained for four kinetic mechanisms using IC engine module of Chemkin 4.1.1.

During combustion lower hydrocarbons, lower molecular weight nitrogen-containing compounds such as ammonia $\left(\mathrm{NH}_{3}\right)$, hydrogen cyanide $(\mathrm{HCN})$ and cyanide (CN) are formed [1,29]. Simulation of CNG combustion in IC engine (Chemkin 4.1.1) predicts the existence and formation of these precursor compounds on NO formation.

Rate of Production (ROP) analysis of each of mechanism was carried out to know which type of reaction contribute the $\mathrm{NO}_{\mathrm{x}}$ formation at typical $3000 \mathrm{~K}$ under stoichiomteric conditions $(\varphi=1.0)$ at moderate speed of $3000 \mathrm{rpm}$. ROP analysis shows the how much a particular reaction contributes in production or consumption of a specie/product. Table 7 shows the important plausible reactions involved in $\mathrm{NO}_{\mathrm{x}}$ formation due to $\mathrm{CNG}$ combustion in IC engine and normalized rate of production coefficients. The positive $(+v e)$ value of Normalized ROP coefficient indicate the production or forward rate is dominant while negative (-ve) value means the consumption or backward rate of reaction is dominate.

In Table 7, it is clear that $\mathrm{NO}_{2}$ is converted to $\mathrm{NO}$ via reaction; $\mathrm{NO}_{2}+\mathrm{M}<=>\mathrm{NO}+\mathrm{O}+\mathrm{M}$ where $\mathrm{M}$ is the third body molecular specie or radical (which may be $\mathrm{OH}$ ). Figure 8 shows the emission data $\mathrm{NO}$ and $\mathrm{NO}_{2}$ from the tested engine data measured at various equivalence ratios. These figures indicate that the $\mathrm{NO}_{\mathrm{x}}$ formation is greatly affected by Fuel/Air Equivalence Ratios. During the experiments, it was observed that as equivalence ratio is increased, the oxygen concentrations were lowered and in parallel burned gas temperature decreased. When mixture was leaned, increasing oxygen concentrations offset the lowered gas temperature and NO emissions get peak concentrations nearly at $\varphi \approx 0.97$ while highest concentrations reached at $\varphi \approx 0.85$.

The $\mathrm{NO}_{\mathrm{x}}$ concentrations showed different character both under fuel lean and fuel rich conditions. Based upon both simulations results and experimental data, it can be concludes that;

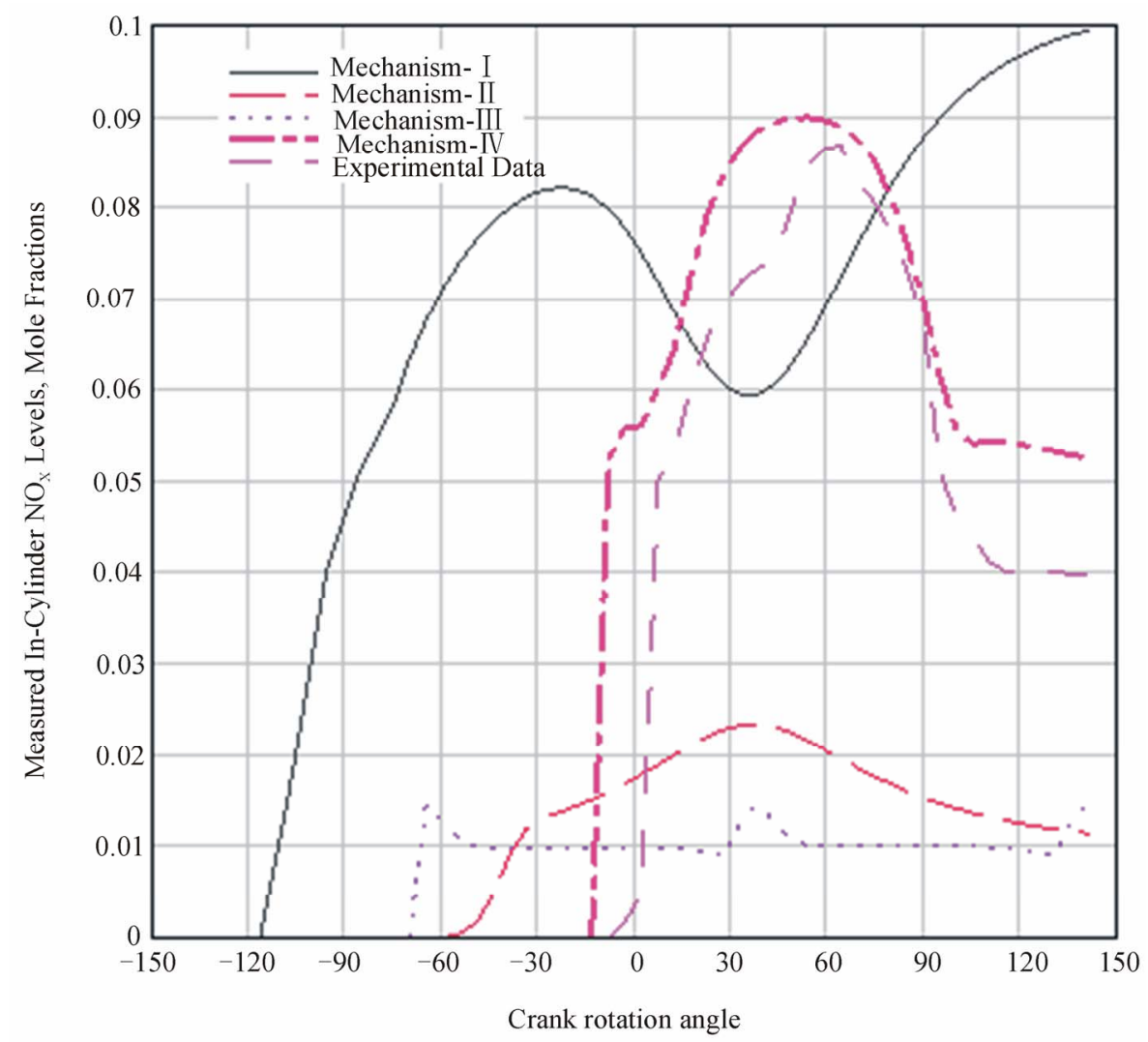

Figure 9. Comparison of $\mathrm{NO}_{\mathrm{x}}$ profiles (with modeled data and experimental data). 
Table 7. Reactions involved in formation and consumption of $\mathrm{NO}_{\mathrm{x}}\left(\mathrm{NO} \& \mathrm{NO}_{2}\right)$ in proposed four kinetic mechanisms with calculated normalized rate of production coefficients.

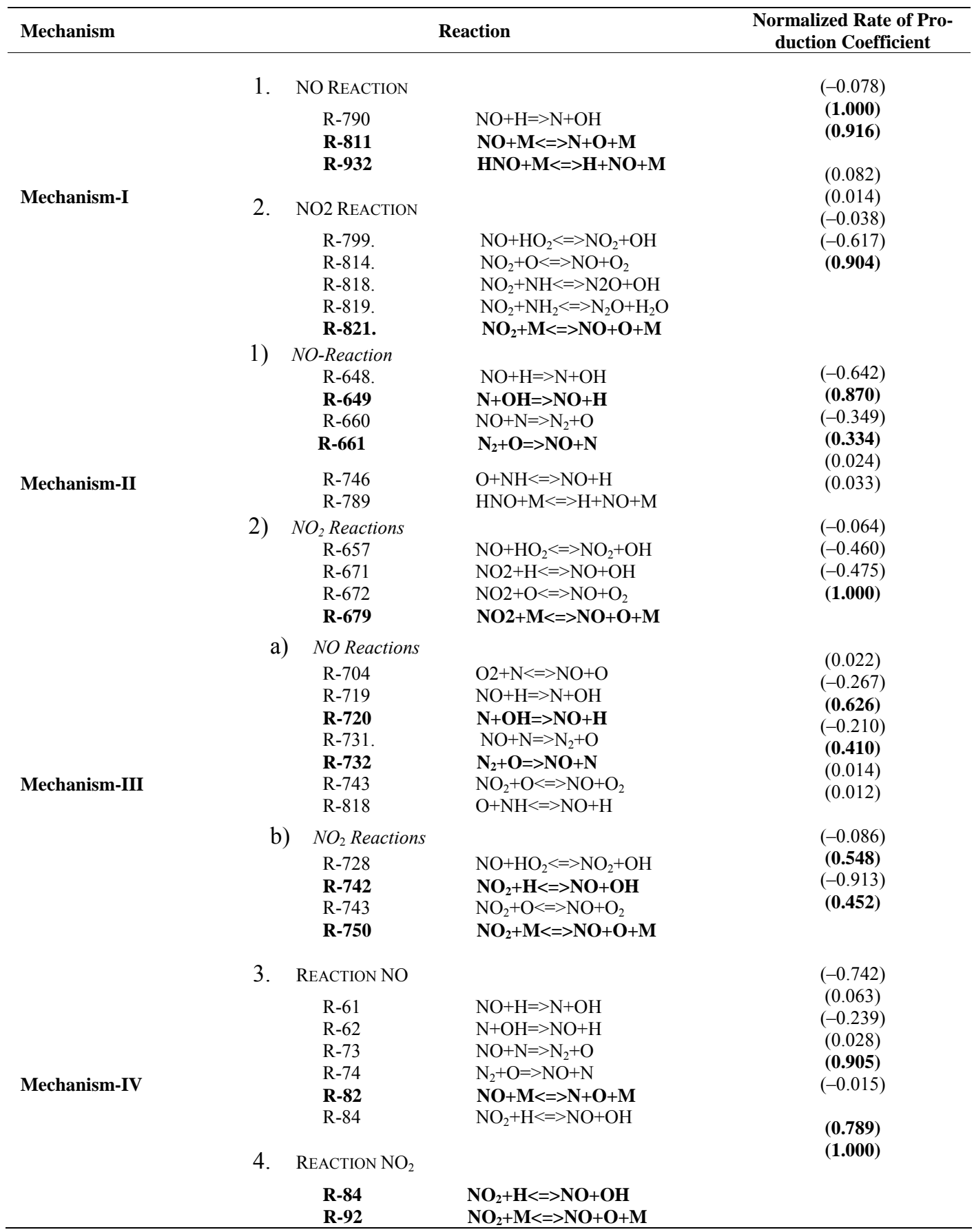

- NO concentration become stable little early in the expansion process and a little conversion of NO may occur in lean fuel mixture conditions.

- In fuel rich mixture, the sharp decrease in NO concentrations occurs from peak values when maximum cylinder pressure is achieved.

The in-cylinder $\mathrm{CO}$ measurements were done through
Rapid Sampling Valve. Figure 10 shows the measurements of CO levels (measured in term of \% while it is then converted to mole fraction and ppm units). The data is plotted against crank angle position. The $\mathrm{CO}$ data was recorded at nearly $-8^{\circ}\left(7.8^{\circ}\right.$ actual). The varying levels of $\mathrm{CO}$ after combustion process shows the occurring of some reactions $\mathrm{CO}$ consumption formed during the com- 


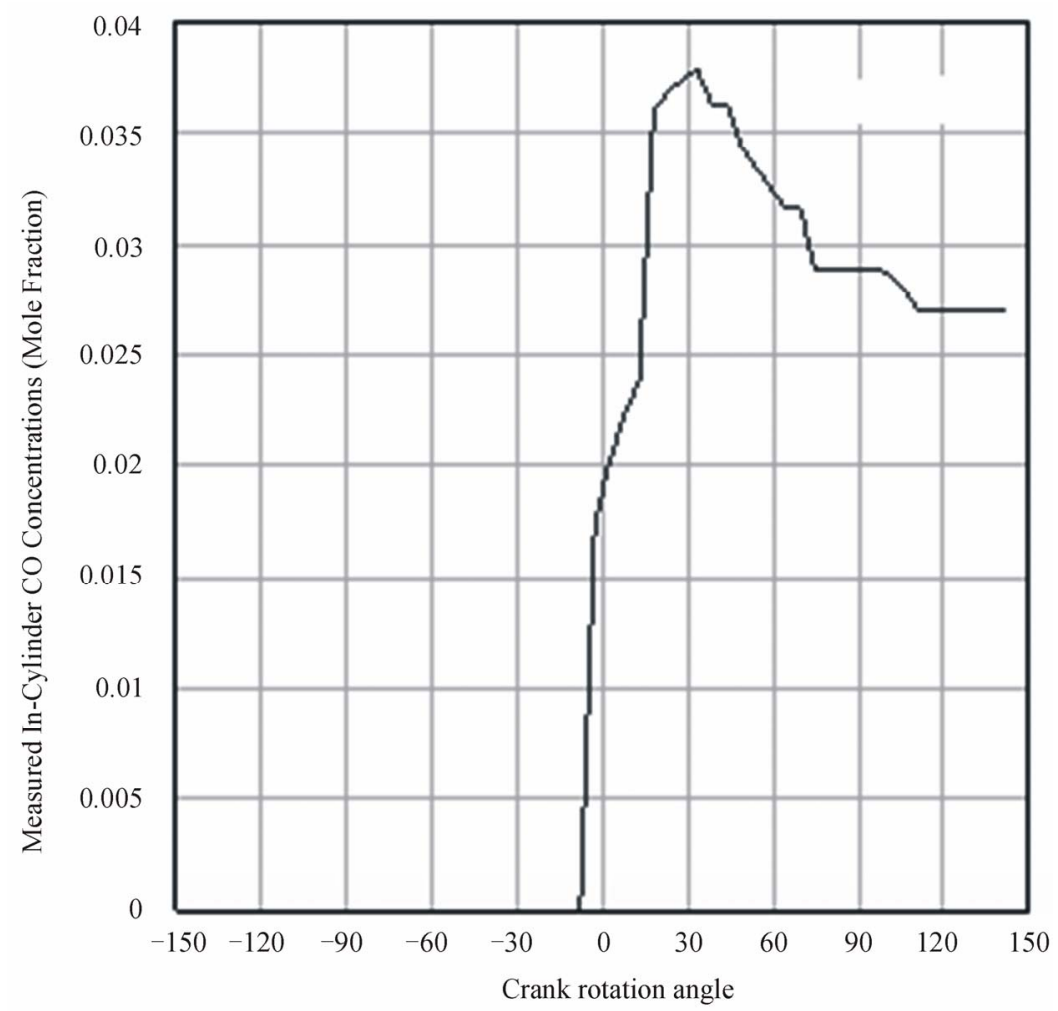

Figure 10. Measured CO concentrations (in-cylinder) for $3000 \mathrm{rpm}, \varphi=1.0$ and $\boldsymbol{P}_{\text {inlet }}=0.67 \mathrm{~atm}$.

bustion phase and freezing of $\mathrm{CO}$ chemistry when used CNG

The experiments were conducted for various equivalence ratios and data was recorded when engine was operated at $3000 \mathrm{rpm}$ and exit temperature was nearly 494 $\mathrm{K}$. The molded data of $\mathrm{CO}$ data was also determined for the four proposed kinetic mechanisms using IC engine module of Chemkin 4.1.1 software. The simulation conditions were set as given in Table 4 and fuels fractions were used as given for CNG in Table 5. The modeled data was compared with the experimental data (collected when engine was operated at $3000 \mathrm{rpm}, \varphi=1.0, P_{\text {inlet }}=$ $0.67 \mathrm{~atm}$ fired with CNG and Figure 11 shows the comparison of modeled data for $\mathrm{CO}$ levels obtained for four proposed kinetic mechanisms. The CO profile for Mechanism-I, Mechanism-II and Mechanism III indicate that these mechanisms seem to be inappropriate for predicting the $\mathrm{CO}$ in IC engine. According to Figure 11, the molded data for Mechanism-IV exhibits closer agreement with experimental measurements.

The major reactions involved in formation and consumption of $\mathrm{CO}$ in the combustion chamber of the tested automobile (IC) engine for proposed kinetic mechanisms are given in Table 8. The reactions are listed according to the normalized rate of production coefficient determined by the ROP analysis of each mechanism.

According to Table 8, the following reaction were proposed to take part in the formation of $\mathrm{CO}$ and shows more contribution) during the combustion of $\mathrm{CNG}$ in tested IC engine;

$$
\begin{gathered}
\mathrm{HNCO}+\mathrm{M}<=>\mathrm{NH}+\mathrm{CO}+\mathrm{M}, \\
\mathrm{NCO}+\mathrm{M}<=>\mathrm{N}+\mathrm{CO}+\mathrm{M}
\end{gathered}
$$

\section{Conclusions}

The proposed mechanisms were successfully implemented to predict the profiles of temperature, pressure and pollutant species in Chemkin 4.1.1. The average measured cylinder pressure varied from $0.61 \mathrm{~atm}$ to $32.62 \mathrm{~atm}$ for six consecutive engine cycles. The highest concentrations of $\mathrm{NO}_{\mathrm{x}}$ were near the stoichiometric conditions and then become lower while $\mathrm{CO}$ level shows increasing trend. The modeled data was compared with the experimental data (measured when engine was operated at $\left.3000 \mathrm{rpm}, \varphi=1.0, P_{\text {inlet }}=0.67 \mathrm{~atm}\right)$ for each proposed mechanisms. The profile for Mechanism-I and Mechanism-II showed very early start of the combustion, which does not agree with the experimental data. Mechanism-III also shows far away behavior from the actual monitored data of the actual engine operation data. The predicted CO profiles for Mechanism-IV exhibits closer agreement with experimental measurements. Although there are some discrepancies exist in the $\mathrm{CO}$ profiles for Mechanism-IV and experimental data but on whole, 


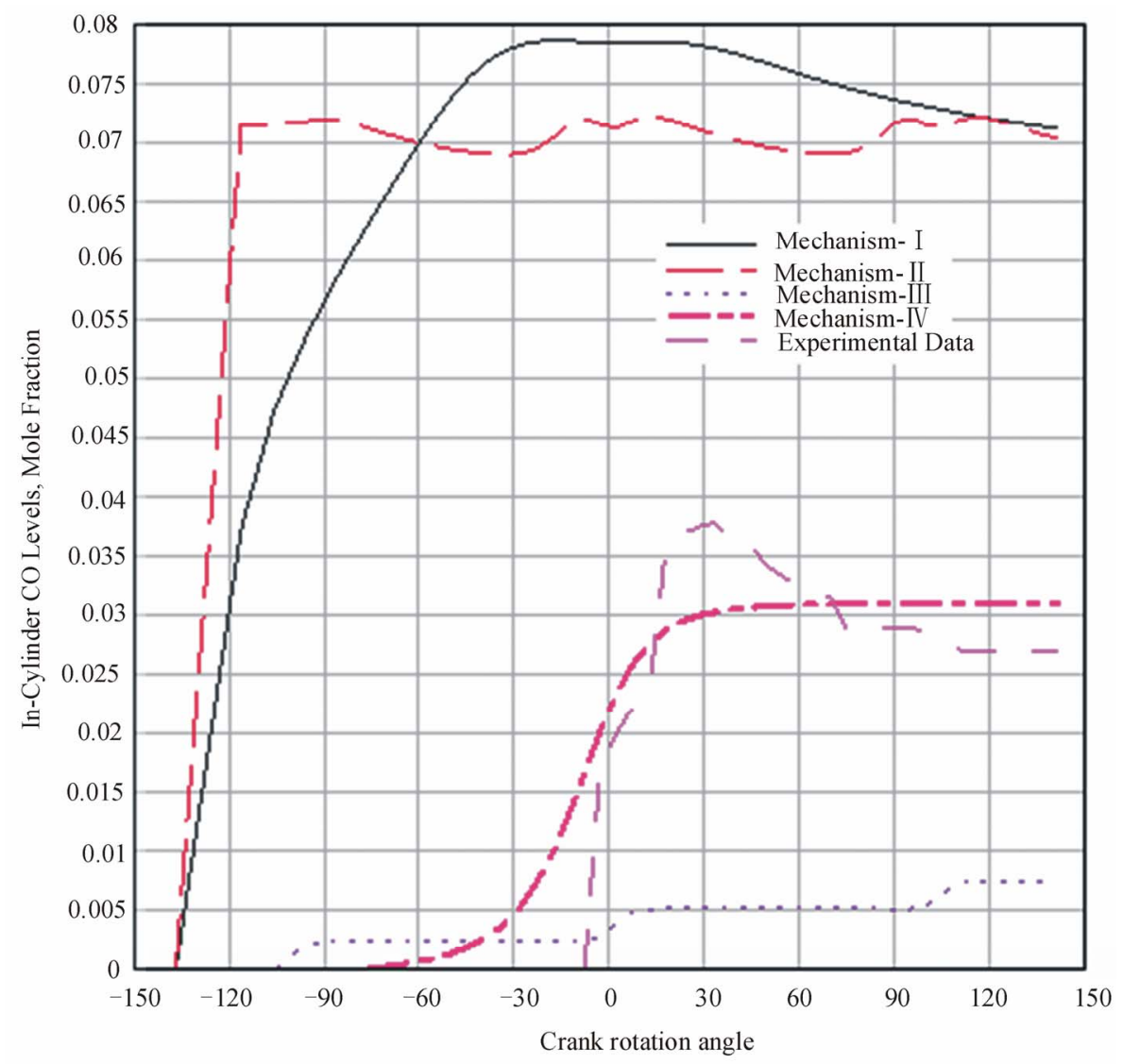

Figure 11. Comparison of CO profiles (with modeled data and experimental data).

Table 8. Reactions in four kinetic mechanisms (proposed) in CO formation and consumption.

\begin{tabular}{|c|c|c|}
\hline Mechanism & Reactions & $\begin{array}{c}\text { Normalized Rate of } \\
\text { Production Coefficient }\end{array}$ \\
\hline Mechanism-I & $\begin{aligned} \mathrm{CO}+\mathrm{N}_{2} \mathrm{O} & =>\mathrm{CO}_{2}+\mathrm{N}_{2} \\
\mathrm{CO}_{2}+\mathrm{N} & =>\mathrm{NO}+\mathrm{CO} \\
\mathrm{HNCO}+\mathrm{M} & <=>\mathrm{NH}+\mathrm{CO}+\mathrm{M} \\
\mathrm{NCO}+\mathrm{M} & <=>\mathrm{N}+\mathrm{CO}+\mathrm{M}\end{aligned}$ & $\begin{array}{c}-0.139 \\
0.740 \\
0.322 \\
1.000\end{array}$ \\
\hline Mechanism-II & $\begin{aligned} \mathrm{CO}+\mathrm{N}_{2} \mathrm{O} & =>\mathrm{CO}_{2}+\mathrm{N}_{2} \\
\mathrm{CO}_{2}+\mathrm{N} & =>\mathrm{NO}+\mathrm{CO} \\
\mathrm{HCN}+\mathrm{O} & =>\mathrm{NH}+\mathrm{CO} \\
\mathrm{NCO}+\mathrm{H} & =>\mathrm{NH}_{2}+\mathrm{CO} \\
\mathrm{HNCO}+\mathrm{M} & =>\mathrm{NH}+\mathrm{CO}+\mathrm{M} \\
\mathrm{H}+\mathrm{NCO} & <=>\mathrm{NH}+\mathrm{CO} \\
\mathrm{O}+\mathrm{CN} & =>\mathrm{CO}+\mathrm{N} \\
\mathrm{O}+\mathrm{NCO} & =>\mathrm{NO}+\mathrm{CO} \\
\mathrm{OH}+\mathrm{NCO} & =>\mathrm{NO}+\mathrm{CO}+\mathrm{H} \\
\mathrm{NCO}+\mathrm{M} & <=>\mathrm{N}+\mathrm{CO}+\mathrm{M}\end{aligned}$ & $\begin{array}{c}-0.013 \\
0.094 \\
0.044 \\
0.119 \\
-0.025 \\
0.304 \\
-0.017 \\
0.290 \\
0.138 \\
-0.945\end{array}$ \\
\hline Mechanism-III & $\begin{aligned} \mathrm{CO}+\mathrm{N}_{2} \mathrm{O} & <=>\mathrm{CO}_{2}+\mathrm{N}_{2} \\
\mathrm{CO} 2+\mathrm{N} & =>\mathrm{NO}+\mathrm{CO} \\
\mathrm{HCN}+\mathrm{O} & <=>\mathrm{NH}+\mathrm{CO} \\
\mathrm{HNCO}+\mathrm{H} & <=>\mathrm{NH}_{2}+\mathrm{CO} \\
\mathrm{H}+\mathrm{NCO} & <=>\mathrm{NH}+\mathrm{CO} \\
\mathrm{O}+\mathrm{NCO} & <=>\mathrm{NO}+\mathrm{CO} \\
\mathrm{OH}+\mathrm{NCO}< & =>\mathrm{NO}+\mathrm{CO}+\mathrm{H} \\
\mathrm{NCO}+\mathrm{M}< & =>\mathrm{N}+\mathrm{CO}+\mathrm{M}\end{aligned}$ & $\begin{array}{c}-0.032 \\
-0.713 \\
0.020 \\
0.056 \\
0.250 \\
0.383 \\
0.285 \\
-0.246\end{array}$ \\
\hline Mechanism-IV & $\begin{aligned} \mathrm{HNCO}+\mathrm{M} & =>\mathrm{NH}+\mathrm{CO}+\mathrm{M} \\
\mathrm{OH}+\mathrm{NCO} & <=>\mathrm{NO}+\mathrm{CO}+\mathrm{H} \\
\mathrm{NCO}+\mathrm{M} & ==\mathrm{N}+\mathrm{CO}+\mathrm{M}\end{aligned}$ & $\begin{array}{l}0.975 \\
0.022 \\
1.000\end{array}$ \\
\hline
\end{tabular}


we can conclude the Mechanism-IV is representative scheme of reactions predicting the combustion in $\mathrm{CNG}$ fired IC engine.

\section{Acknowledgements}

Authors are thankful to Mrs Warth, NANCR, France for providing copy of EXGAS software free of cost. Authors appreciate the technical support of Mr. Ahmad Din of Rafae Engineering for development of experimental setup. We also extend our gratitude to the Higher Education Commission of Pakistan for sponsoring this research work.

\section{References}

[1] J. B. Heywood, "Internal Combustion Engines Fundamentals," McGraw-Hill, Science/Engineering/Math, New York, 1988.

[2] Q. P. Zheng, H. M. Zhang and D. F. Zhang, "A Computational Study of Combustion in Compression Ignition Natural Gas Engine with Separated Chamber," Fuel, Vol. 84, No. 12-13, 2005, pp. 1515-1523.

[3] M. U. Aslam, H. H. Masjuki, M. A. Kalam, H. Abdesselam, T. M. I. Mahlia and M. A. Amalina, "An Experimental Investigation of Cng as an Alternative Fuel for a Retrofitted Gasoline Vehicle," Fuel, Vol. 85, No. 5-6, 2006, pp. 717-724.

[4] S. Shiga, S. Ozone, H. T. C. Machacon, T. Karasawa, H. Nakamura, T. Ueda, N. Jingu, Z. Huang, M. Tsue and M. Kono, "A Study of the Combustion and Emission Characteristics of Compressed-Natural-Gas Direct-Injection Stratified Combustion Using a Rapid-Compression-Machine," Combustion and Flame, Vol. 129, No. 1-2, 2002, pp. 1-10.

[5] D. Zhang and S. H. Frankel, "A Numerical Study of Natural Gas Combustion in a Lean Burn Engine," Fuel, Vol. 77, No. 12, 1998, pp. 1339-1347.

[6] J. Kusaka, T. Okamoto, Y. Daisho, R. Kihara and T. Saito, "Combustion and Exhaust Gas Emission Characteristics of a Diesel Engine Dual-Fueled with Natural Gas," JSAE Review, Vol. 21, No. 4, 2000, pp. 489-496.

[7] T. Ando, Y. Isobe, D. Sunohara, Y. Daisho and J. Kusaka, "Homogeneous Charge Compression Ignition and Combustion Characteristics of Natural Gas Mixtures: The Visualization and Analysis of Combustion," JSAE Review, Vol. 24, No. 1, 2003, pp. 33-40.

[8] C. K. Westbrook, "Applying Chemical Kinetics to Natural Gas Combustion Problems," Report No. PB-86-168770/ XAB, Lawrence Livermore National Laboratory, Livermore, 1985.

[9] P. Glarborg, J. A. Miller and R. J. Kee, "Kinetic Modelling and Sensitivity Analysis of Nitrogen Oxide Formation in Well Stirred Reactors," Combustion and Flame, Vol. 65, No. 2, 1986, pp. 177-202.

[10] J. A. Miller and C. T. Bow man, "Mechanism and Mod- eling of Nitrogen Chemistry in Combustion," Progress in Energy and Combustion Sciences, Vol. 15, No. 4, 1989, pp. 287-338.

[11] A. A. Konnov, "Detailed Reaction Mechanism for Small Hydrocarbons Combustion," Release 0.5, 2000. http://homepages.vub.ac.be/ akonnov/

[12] K. J. Hughes, T. Tur'anyi, A. R. Clague and M. J. Pilling, "Development and Testing of a Comprehensive Chemical Mechanism for the Oxidation of Methane," International Journal of Chemical Kinetics, Vol. 33, No. 9, 2001, pp. 513-538

[13] G. P. Smith, et al., Grimesh 3.0, http://www.me.berkeley.edu/gri_mech

[14] C. K. Westbrook and F. L. Dryer, "Simplified Reaction Mechanisms for the Oxidation of Hydrocarbon Fuels in Flames," Combustion Sciences and Technologies, Vol. 27, No. 1-2, 1981, pp. 31-43.

[15] J. Duterque, B. Roland and T. Helene, "Study of QuasiGlobal Schemes for Hydrocarbon Combustion," Combustion Science and Technology, Vol. 26, No. 1-2, 1981, pp. $1-15$.

[16] N. N. Peters, "Numerical and Asymptotic Analysis of Systematically Reduced Reaction Schemes for Hydrocarbon Flames: Numerical Simulation of Combustion Phenomena," In: R. Glowinski, B. Larrouturou and R. Temam, Eds., Lecture Notes in Physics, Proceedings of the Symposium Held at INRIA Sophia-Antipolis, France, Vol. 241, 21-24 May 1985, pp. 90-109.

[17] D. J. Hautmann, F. L. Dryer, K. P. Schug and I. Glassman, "A Multiple-Step Overall Kinetic Mechanism for the Oxidation of Hydrocarbons," Combustion Sciences and Technologies, Vol. 25, No. 5-6, 1981, pp. 219-235.

[18] W. P. Jones and R. P. Lindstedt, "Global Reaction Schemes for Hydrocarbon Combustion, Global Reaction Schemes for Hydrocarbon Combustion," Combustion and Flame, Vol. 73, No. 3, 1988, pp. 233-249.

[19] R. B. Edelman and O. F. Fortune, "A Quasi-Global Chemical Kinetic Model for the Finite Rate Combustion of Hydrocarbon Fuels with Application to Turbulent Burning and Mixing in Hypersonic Engines and Nozzles," American Institute of Aeronautics and Astronautics, 1969, pp. 69-86.

[20] R. B. Edelman and P. T. Harsha, "Laminar and turbulent Gas Dynamics in Combustors-Current Status," Progress in Energy and Combustion Sciences, Vol. 4, No. 1, 1978, pp. 1-62.

[21] C. Muller, V. Michel, G. Scacchi and G M. J. C^ome, "THERGAS: A Computer Program for the Evaluation of Thermochemical Data of Molecules and Free Radicals In the Gas Phase," Journal de Chemie Physique, Vol. 92, No. 5, 1995, pp. 1154-1178.

[22] P. A. Glaude, F. Batttin-Leclerc, R. Fournet, V. Warth and G. M. Come, "Construction and Simplification of a Model for the Oxidation of Alkanes," Combustion and Flame, Vol. 122, No. 4, 2000, pp. 451-462.

[23] B. F. Leclerc, R. Bounaceur, G. M. C^ome, R. Fournet, P. A. Glaude, G. Scacchi and V. Warth, "EXGAS User's 
Guide," Nancy, France, 2004.

[24] G. M. C^ome, V. Warth, P. A. Glaude, R. Fournet, F. Battin-Leclerc and G. Scacchi, "Computer Aided Design of Gas-Phase Oxidation Mechanisms: Application to the Modelling of Normal Heptane and Iso-Octane Oxidation," Proceedings of the 26th International Symposium on Combustion, the Combustion Institute, Pittsburgh, 1996, p. 755.

[25] P. A. Glaude, V. Warth, R. Fournet, F. Battin-Leclerc, G. M. C^ome and G. Scacchi, Bull Soc Chim Belg, Vol. 106, No. 6, 1997, p. 343.

[26] P. A. Glaude, V. Warth, R. Fournet, F. Battin-Leclerc, G. Scacchi and G. M. C’ome, "Modeling of the Oxidation of n-octane and n-decane Using an Automatic Generation Of Mechanisms," International Journal of Chemical Kinetics, Vol. 30, No. 12, 1998, pp. 949-959. doi:10.1002/(SICI)1097-4601(1998)30:12<949::AID-KI $\mathrm{N} 10>3.0 . \mathrm{CO} ; 2-\mathrm{G}$

[27] M. Mansha, A. R. Saleemi and M. Badar Ghauri, "Kinetic Models of Natural Gas Combustion in an Internal Combustion Engine," Journal of Natural Gas Chemistry, Vol. 19, No. 1, 2010, pp. 6-14.

[28] M. Mansha, A. R. Saleemi, M. Ghauri Badar and N. Ramzan, "Development and Testing of a Detailed Kinetics Mechanism of Natural Gas Combustion in IC Engine," Journal of Natural Gas Chemistry, Vol. 19, No. 2, 2010, pp. 97-106. doi:10.1016/S1003-9953(09)60039-6

[29] Reaction Design, Theory Manual, Chemkin 4.1.1 Software, (2004).
[30] F. EI-Mahallawy and S. EI-Din Habik, "Fundamentals and Technology of Combustion," Elsevier Science Ltd, UK, 2002.

[31] R. Ennetta, M. Hamdi and R. Said, "Comparison of Different Chemical Kinetic Mechanisms of Methane Combustion in an Internal Combustion Engine Configuration, Thermal Science, Vol. 12, No. 1, 2008, pp. 43-51. doi:10.2298/TSCI0801043E

[32] L. Cao, H. Zhao and X. Jiang, "Analysis of Controlled Auto-Ignition/HCCI Combustion in a Direct Injection Gasoline Engine with Single and Split Fuel Injections," Combustion Science and Technology, Vol. 180, No. 1, 2008, pp. 176-205.

[33] N. M. I. N.Ibrahim, R. A. Bakar, A. R. Ismail and I. Ali, "Analysis of Engine Speed Effect on Temperature and Pressure of Engine Based on Experiment and Computational Simulation," Journal of Applied Sciences Research, Vol. 4, No. 1, 2008, pp. 76-83.

[34] Y. Bakhshan and S. Abdullah, "Study of CNG Combustion under Internal Combustion Engine Conditions, Part II Using Multi dimensional Modeling," Algerian Journal of Applied Fluid Mechanics, Vol. 1, No. 1, 2008, pp. 10-18.

[35] S. Abdullah, W. H. Kurniawan and A. Shamsudeen, "Numerical Analysis of the Combustion Process in a Compressed Natural Gas Direct Injection Engine," Algerian Journal of Applied Fluid Mechanics, Vol. 1, No. 2, 2008, pp. 65-86. 